\title{
Refractory Anal Carcinoma
}

National Cancer Institute

\section{Source}

National Cancer Institute. Refractory Anal Carcinoma. NCI Thesaurus. Code C137857.

Anal carcinoma that does not respond to treatment. 